\title{
Educational inequalities in Global Activity Limitation Indicator disability in 28 European Countries: Does the choice of survey matter?
}

\author{
Jose R. Rubio-Valverde ${ }^{1} \cdot$ Wilma J. Nusselder ${ }^{1} \cdot$ Johan P. Mackenbach $^{1}$
}

Received: 8 December 2017/Revised: 22 October 2018/Accepted: 11 November 2018/Published online: 26 November 2018

(C) The Author(s) 2018

\begin{abstract}
Objectives To assess the sensitivity of prevalence and inequality estimates of Global Activity Limitation Indicator (GALI) to the choice of survey in European countries.

Methods We use logistic regression to estimate adjusted risk ratios, quantifying differences in prevalence and educational inequalities, the impact of survey characteristics and Kendall's tau to assess similarity in country rankings between surveys. We include the European Health Interview Survey (EHIS), European Social Survey (ESS) and European Union Statistics on Income and Living Conditions (EU-SILC).

Results EHIS estimates higher prevalence than EU-SILC 17\% (men) and 23\% (women), and ESS 24\% (men) and 29\% (women). Prevalence does not differ significantly between EU-SILC and ESS. EU-SILC estimates 52.5\% (men) and 28.1\% (women) higher inequalities than EHIS and 63.2\% (men) and 32.7\% (women) higher inequalities than ESS. Survey characteristics do not account for differences in prevalence or inequalities. Country rankings do not agree for prevalence or inequalities.

Conclusions Survey choice strongly impacts estimates of GALI prevalence and educational inequalities. Further study is necessary to understand these discrepancies. Caution is required when using these surveys for cross-country comparisons of (educational inequalities in) GALI disability.
\end{abstract}

Keywords GALI $\cdot$ Survey $\cdot$ Educational inequalities $\cdot$ International comparison

\section{Introduction}

Composite health metrics that combine data on mortality and health into a single measure of health expectancy are increasingly used to describe and understand changes in population health (Hyder et al. 2012; Brønnum-Hansen et al. 2015). The construction of these measures requires selecting from a range of health indicators. One of the most used indicators is the Global Activity Limitation Indicator (GALI), which can be combined with mortality data to estimate Healthy Life Years, the disability-free life

Electronic supplementary material The online version of this article (https://doi.org/10.1007/s00038-018-1174-7) contains supplementary material, which is available to authorized users.

Jose R. Rubio-Valverde

j.rubiovalverde@erasmusmc.nl

1 Department of Public Health, Erasmus Medical Center, P.O. Box 2040, 3000 CA Rotterdam, Netherlands expectancy measure that has been selected by the European Commission for standard use across Europe. GALI is part of the Minimum European Health module (MEHM). The importance of the GALI indicator is reflected in its presence in many national and cross-national surveys like the European Social Survey (ESS), the European Health Interview Survey (EHIS) and the European Statistics on Income and Living Conditions (EU-SILC).

The GALI has been shown to have good and sufficient concurrent and predictive validity, and reliability as well as fitting all conceptual characteristics of a global measure of participation restriction (Van Oyen et al. 2018). However, the indicator is self-reported, and is subject to variations in the tendency to report health problems (Berger et al. 2015b; Jürges 2007).

It is unknown whether different surveys that measure the GALI indicator lead to similar conclusions regarding prevalence and educational inequalities. Surveys differ in various characteristics, including sampling design, method of data collection, response rate, whether or not proxy 
respondents are allowed and the phrasing of the GALI question (EHLEIS 2011).

Prior research on self-reported health (SRH) based on three cross-national surveys in 10 European countries (EUSILC; Survey of Health, Aging and Retirement in Europe (SHARE) and ESS) showed that the prevalence of lessthan-good SRH varies significantly across surveys and that differences between surveys in response rate, sample size and collection mode contributed to these differences (Croezen et al. 2016). A second study by Toch-Marquardt (2017) on occupational inequalities in SRH comparing four European surveys (ESS; EU-SILC; European Working Conditions Survey (EWCS); and International Social Survey Programme (ISSP), found that both prevalence and occupational inequalities in SRH vary significantly by survey, and was unable to detect regional patterns in inequalities that are consistent across surveys. For smoking, prevalence and educational inequalities also vary by survey (Kulik et al. 2014).

For the GALI indicator, evidence is lacking whether the prevalence levels and educational differences differ between surveys and whether survey characteristics could explain possible differences and hence inform the choice which survey to use, or to allow obtaining a pooled estimate for a specific combination of survey characteristics. Therefore, the primary aim of this paper is to assess whether three widely used nationally representative European surveys provide similar or different estimates of prevalence of GALI disability and of educational inequalities in GALI disability in Europe. The secondary aim is to assess the role of survey characteristics in these variations between the surveys.

\section{Methods}

\section{Data}

\section{Description of surveys}

The European Health Interview Survey (EHIS) mainly gathers health-related indicators. It has four modules including variables of health status, healthcare use, health determinants and socioeconomic background. The survey targets individuals above 15 years old living in private households. It was implemented from 2006 to 2009 in 17 EU member states and is repeated every 5 years. We included all 15 countries from the first wave of EHIS, with a total sample size of 125,293 persons.

The European Social Survey (ESS) is a biennial crossnational survey starting from 2001. It surveys beliefs, attitudes and behavior patterns of populations of more than 30 countries. The samples are representative of all individuals over 15 years old living in private households and have a minimum size of 1.500 individuals, except for countries with less than 2 million inhabitants. We included data for 27 countries for 2008, 2010 and 2012, for a total of 103,829 individuals (ESS 2016).

The European Union Statistics on Living Conditions (EU-SILC) survey provides annual data on variables on poverty, income, social exclusion and living conditions. The survey was launched in 2003, and has extended its coverage to the 28 member states of the enlarged European Union. The target population is all private households and their members living in the country's territory. All household members are surveyed, and only those above 16 years are interviewed. EU-SILC provides both cross-sectional and longitudinal data. We have pooled the cross-sectional data for the years 2008 and 2012. Considering the rotating panel structure (Eurostat 2016), intermediate years are excluded to avoid including subject more than once. We included 28 countries from EU-SILC, with a total sample size of 603,785 .

Countries included in our analysis must be present in at least two of the three surveys. We restricted the analysis to persons between 30 and 79 years old because below age 30 not everybody has completed his/her education, and above age 80 an increasing fraction of the population is institutionalized. ESS, EU-SILC and EHIS include only persons living in private households. Because of lack of sample representativeness in EU-SILC, we excluded Luxembourg and Malta (Cambois et al. 2016b).

The countries included in our analysis were Denmark, Finland, Norway, Sweden, the UK, Ireland, the Netherlands, Belgium, Germany, Austria, Switzerland, France, Spain, Italy, Greece, Cyprus, Slovenia, Croatia, Czech Republic, Slovakia, Hungary, Poland, Bulgaria, Romania, Latvia, Lithuania and Estonia. For clarity of presentation, we present the countries according to geographical region.

\section{Measure of disability}

The GALI question is: "For at least the past 6 months, to what extent have you been limited in activities people usually do?". EHIS used the standard version of the question across all countries, and ESS omitted the time reference in the question. Countries in EU-SILC had more diverse implementation of the question, with 13 using the standard GALI question in 2008, and variations including the omission of the time frame, changing the generic "activities people do" for a more personal reference; and breaking the single question into parts. The response categories were similar across surveys, with three potential responses ("Yes, a lot"; "Yes, some"; "No"). For our analysis, we combined yes categories. 


\section{Measure of socioeconomic status}

All three surveys provided ISCED-97 educational attainment. We combined the ISCED categories to form 3 levels of education: low, medium and high, corresponding to ISCED categories 0-2, 3-4 and 5-6, respectively.

\section{Survey characteristics}

We collected information on survey characteristics from technical and quality reports of the different surveys: individual response rate (\%), sample size (in thousands), sampling design in three categories (simple random one/multistage; stratified random one/multistage; stratified systematic one/multistage), proxy respondents (as a binary variable) and collection mode in three categories (present interviewer (PAPI-Paper and Pencil Interviewing-and CAPI-Computer-Assisted Personal Interviewing), remote interviewer (CATI-Computer-Assisted Telephone Interview) and other (including countries that use several modes of data collection and Germany in EU-SILC, which uses a self-administered questionnaire)). Information on survey characteristics is presented in Online Resource 1.

\section{Statistical analyses}

\section{Prevalence}

We calculated for each country and survey age-standardized prevalence of GALI disability by gender, using the 2013 European Standard Population.

We used logistic regression and the post-estimation command adjrr in STATA, and obtained adjusted risk ratios (ARRs) for pairs of surveys (Norton et al. 2013). These regression models included age category (30-34; $15-39 ; \ldots 75-79)$ and survey as independent variables and were stratified by country and gender. The ARRs indicate whether differences in prevalence exist between surveys relative to the baseline survey.

Next, we pooled data across countries. This second set of regression models additionally included country (with 27 levels) and education. The ARR indicates whether on average differences in prevalence exist between surveys while controlling for country and education. Standard errors were clustered at the country level to account for potential correlation of individuals within a country. We repeated this analysis, stratified by education to assess if survey variation in prevalence of GALI disability is different across educational groups.

\section{Educational inequalities}

Similar to the prevalence analyses, we started with separate analyses for country, gender and survey. We used logistic regression models with age category and education as independent variables. We derived ARRs for low versus high educated to compare the variation in educational inequalities in GALI disability for individual countries for each survey and gender. To test whether the educational inequalities are significantly different across pairs of surveys within a country, we pooled data for each pair of survey, added a survey interaction with education and conducted likelihood ratio (LR) tests to compare between models with and without this interaction term.

Next, we pooled data across countries to examine the average difference of the educational inequalities across the three surveys. The adjrr command calculated educational ARRs using the coefficients for education, survey and the interaction between them and indicates surveyspecific educational ARR, when controlling for age category and country.

\section{Survey characteristics}

We extended the survey-country pooled models for prevalence and inequalities with survey characteristics to assess to what extent variations in survey characteristics explain differences between surveys. This involved assessing the significance of each survey characteristic individually using Wald tests. We then included all statistically significant survey characteristics and the interactions between these survey characteristics and education in the final model.

We assessed whether the inclusion of the survey characteristics and their interactions altered the derived ARR for differences in prevalence between surveys. These regression models combined survey characteristics at the survey level with individual level data, but the adjrr STATA command to derive ARRs has not been adapted for the multi-level setting. We conducted robustness analyses using multi-level logistic regression, with country at the higher level and survey nested within country (included as a random effect), and compared the results with the standard logistic regression. Taking into account the multilevel structure of the data did not alter our results (Online Resource 4).

\section{Ranking comparison}

We used age-standardized prevalences and country educational inequalities (ARRs) to create rankings of countries in terms of the two outcomes. We paired surveys and restricted the rank comparison only to countries present in 
both surveys. For each pair of rankings, we estimated Kendall's tau and its associated $p$ value. A value of -1 implies perfect reversal of the rankings, while a value of 1 implies perfect agreement. We chose Kendal's tau over other rank correlation measures like Spearman's correlation because it has been shown to be slightly more robust and efficient (Croux and Dehon 2010). The ranking comparisons were stratified by gender.

We focused on relative educational inequalities in GALI prevalence. All analyses were repeated for absolute educational inequalities (Online Resource 2).

\section{Results}

\section{Prevalence of GALI disability}

Table 1 shows the age-standardized GALI prevalence and the ARRs by survey for each country, stratified by gender. Confidence intervals can be found in Online Resource 3.

There is substantial variation in prevalence between surveys. For men, the ARRs using as reference EU-SILC indicate that EHIS provides statistically significantly higher prevalence estimates for 11 of the 15 countries, while ESS yields lower prevalence for 2 countries (Belgium, Cyprus) and no significant difference for the 2 remaining countries (Greece, Romania). For women, EHIS estimates higher prevalence than EU-SILC in 12 countries, with the 3 remaining countries showing no statistically significant differences between the two surveys. When comparing ESS with EU-SILC, the results are diverse. For men in 11 of the 27 countries, ESS yields significantly higher prevalence estimates; in 10 lower and in 6 not statistically different. Women display the same pattern.

When comparing ESS and EHIS, for men, ESS produces higher prevalence estimates for one country (Belgium), lower prevalence for 9 countries and no statistically significant difference for 4 countries. Women display a similar pattern, with EHIS estimating higher prevalence also for Poland.

Table 2 (Model 1) presents the average across all countries of the patterns described above for men and women. For men, as compared to EU-SILC, EHIS estimates on average $17 \%$ higher prevalence $(\mathrm{ARR}=1.17, \mathrm{CI}$ $1.09,1.25)$, and ESS a non-statistically significant $6 \%$ lower prevalence $(\mathrm{ARR}=0.94$, CI 0.84, 1.05). For women, EHIS estimates $23 \%$ higher prevalence $(\mathrm{ARR}=1.23, \mathrm{CI}$ $1.06,1.30)$ and a non-significant $5 \%$ lower prevalence $(\mathrm{ARR}=0.95, \mathrm{CI} 0.85,1.06)$. The average difference in prevalence for ESS is not statistically different from EHIS.

The stratified analysis by education shows that ESS estimates statistically significantly lower prevalence than EU-SILC and EHIS for the low educated group (Table 3).
The difference as compared to EU-SILC is $12 \%(\mathrm{ARR}=$ $0.88,95 \%$ CI $0.81,0.97)$ for men and 9\% $(A R R=0.91$, $95 \%$ CI $0.83,0.99)$ for women. The results for other educational levels are consistent with the results from the model with all educational levels showing higher prevalence for EHIS than EU-SILC, although the difference is larger for the high educated $(\mathrm{ARR}=1.31,95 \%$ CI 1.19, $1.42)$ than for the low educated $(A R R=1.07,95 \%$ CI 1.01 , 1.13). Women display a similar pattern.

\section{Educational inequalities between surveys}

Figure 1 shows educational differences in GALI prevalence by country, survey and gender (CIs are presented in Online Resource 5). For both genders and most countries, the ARRs are substantially higher than 1, indicating a higher prevalence of GALI disability among the low educated as compared to the high educated, although several exceptions exist. These include Czech Republic (EHIS men and women), Slovenia (EHIS men), Slovakia (EHIS and ESS men), Italy (ESS men; EHIS women), Portugal (ESS men), Cyprus (ESS men), Greece (ESS men; EHIS women), Romania (ESS men; EHIS women) and Croatia (EHIS women).

The average ARR for men for all countries combined for EU-SILC is 1.93 (95\% CI 1.79-2.07) as compared to 1.61 (95\% CI 1.46-1.66) for EHIS (Table 4, Model 1). This corresponds to $52.5 \%$ higher educational differences in EU-SILC than in EHIS. When comparing EU-SILC and ESS, estimates of ARR are $63.2 \%$ higher than in ESS $(1.93 / 1.57) /(1.57-1.00)$. For women in EU-SILC, the differences were $28.1 \%$ higher for EU-SILC (1.73-1.57)/ (1.57-1.00) as compared to EHIS and $32.7 \%$ higher as compared to ESS (1.73-1.55)/(1.55-1.00).

\section{Survey characteristics}

We find a statistically significant association between collection mode and GALI prevalence only; none of the other survey characteristics is associated with GALI prevalence. Relative to present interviewer (PAPI and CAPI), remote interviewer (CATI) is associated with a lower GALI prevalence for men $(\mathrm{ARR}=0.81,95 \% \mathrm{CI} 0.68-0.99)$ and women $(\mathrm{ARR}=0.83,95 \%$ CI 0.70-0.96). Controlling for collection mode does not change the difference between EHIS and EU-SILC as can be seen by comparing the ARR for survey according to Model $1(\mathrm{ARR}=1.17,95 \% \mathrm{CI}$ $1.09,1.25)$ with that of Model $5(\mathrm{ARR}=1.18,95 \% \mathrm{CI}$ $1.10,1.26)$ for men and by comparing Model 1 (ARR = $1.23,95 \%$ CI $1.06,1.30)$ with Model 5 (ARR $=1.25,95 \%$ CI 1.16, 1.31) for women.

For the educational inequalities, only the inclusion of collection mode has a modest impact on the survey-specific 
Table 1 Age-standardized disability prevalence (age 30-79) in 28 European countries by gender and survey (European Health Interview Survey 2006-2009; European Social Survey 2008, 2010, 2012;
European Union Statistics on Income and Living conditions 2008, 2012) and adjusted risk ratios comparing prevalence estimates between surveys

\begin{tabular}{|c|c|c|c|c|c|}
\hline \multicolumn{3}{|c|}{ Prevalence $(\%)^{\mathrm{a}}$} & \multicolumn{3}{|c|}{ Adjusted Risk Ratios (ARRs) ${ }^{\mathrm{b}}$} \\
\hline $\begin{array}{l}\text { EU- } \\
\text { SILC }\end{array}$ & EHIS & ESS & $\begin{array}{l}\text { EHIS } \\
\text { versus } \\
\text { EU-SILC }\end{array}$ & $\begin{array}{l}\text { ESS } \\
\text { versus } \\
\text { EU-SILC }\end{array}$ & $\begin{array}{l}\text { ESS } \\
\text { versus } \\
\text { EHIS }\end{array}$ \\
\hline
\end{tabular}

\begin{tabular}{ll} 
Prevalence $^{\mathrm{a}}$ \\
\hline EU- EHIS ESS \\
SILC
\end{tabular}
Adjusted Risk Ratios (ARRs)

\begin{tabular}{lll}
\hline EHIS & ESS & ESS \\
versus & versus & versus \\
EU-SILC & EU-SILC & EHIS
\end{tabular}

\begin{tabular}{|c|c|c|c|c|c|c|c|c|c|c|c|c|c|}
\hline \multicolumn{7}{|l|}{ Males } & \multicolumn{7}{|l|}{ Females } \\
\hline Finland & 29 & - & 33 & - & 1.10 & - & Finland & 32 & - & 32 & - & 0.96 & - \\
\hline Sweden & 13 & - & 25 & - & 1.8 & - & Sweden & 19 & - & 28 & - & 1.49 & - \\
\hline Norway & 11 & - & 24 & - & 2.02 & - & Norway & 18 & - & 29 & - & 1.58 & - \\
\hline Denmark & 24 & - & 23 & - & 0.97 & - & Denmark & 29 & - & 29 & - & 1.02 & - \\
\hline UK & 19 & - & 24 & - & 1.21 & - & UK & 22 & - & 26 & - & 1.15 & - \\
\hline Ireland & 19 & - & 18 & - & 0.92 & - & Ireland & 20 & - & 15 & - & 0.77 & - \\
\hline Netherlands & 23 & - & 21 & - & 0.9 & - & Netherlands & 31 & - & 30 & - & 0.95 & - \\
\hline Belgium & 20 & 19 & 23 & 0.92 & 1.11 & 1.21 & Belgium & 23 & 24 & 26 & 0.93 & 1.09 & 1.07 \\
\hline Germany & 33 & - & 30 & - & 0.91 & - & Germany & 33 & - & 30 & - & 0.87 & - \\
\hline Austria & 28 & 34 & - & 1.19 & - & - & Austria & 28 & 35 & - & 1.22 & - & - \\
\hline Switzerland & 21 & - & 17 & - & 0.95 & - & Switzerland & 24 & - & 20 & - & 0.85 & - \\
\hline France & 22 & 24 & 23 & 1.09 & 1.03 & 0.95 & France & 23 & 27 & 24 & 1.11 & 0.99 & 0.89 \\
\hline Spain & 20 & 21 & 12 & 1.04 & 0.62 & 0.59 & Spain & 23 & 28 & 18 & 1.18 & 0.81 & 0.68 \\
\hline Portugal & 23 & - & 14 & - & 0.6 & - & Portugal & 29 & - & 17 & - & 0.62 & - \\
\hline Italy & 24 & - & 16 & - & 0.71 & - & Italy & 27 & - & 18 & - & 0.71 & - \\
\hline Greece & 17 & 17 & 10 & 0.97 & 0.6 & 0.61 & Greece & 20 & 26 & 16 & 1.21 & 0.82 & 0.67 \\
\hline Cyprus & 21 & 18 & 16 & 0.89 & 0.78 & 0.88 & Cyprus & 23 & 22 & 22 & 1 & 0.99 & 0.98 \\
\hline Slovenia & 29 & 36 & 30 & 1.21 & 1.03 & 0.85 & Slovenia & 31 & 41 & 30 & 1.28 & 0.95 & 0.74 \\
\hline Croatia & 21 & - & 28 & - & 1.25 & - & Croatia & 21 & - & 24 & - & 1.12 & - \\
\hline Czech Rep. & 21 & 30 & 26 & 1.37 & 1.23 & 0.9 & Czech Rep. & 22 & 30 & 32 & 1.29 & 1.4 & 1.09 \\
\hline Slovakia & 35 & 42 & 24 & 1.21 & 0.7 & 0.57 & Slovakia & 39 & 47 & 27 & 1.19 & 0.72 & 0.62 \\
\hline Hungary & 26 & 40 & 29 & 1.47 & 1.08 & 0.74 & Hungary & 28 & 45 & 30 & 1.46 & 1.03 & 0.7 \\
\hline Poland & 23 & 27 & 28 & 1.13 & 1.2 & 1.06 & Poland & 23 & 28 & 31 & 1.17 & 1.26 & 1.08 \\
\hline Bulgaria & 15 & 20 & 14 & 1.36 & 0.91 & 0.67 & Bulgaria & 16 & 25 & 16 & 1.53 & 1.01 & 0.66 \\
\hline Romania & 21 & 22 & 17 & 1.05 & 0.77 & 0.74 & Romania & 26 & 29 & 21 & 1.06 & 0.76 & 0.71 \\
\hline Latvia & 30 & 47 & 36 & 1.51 & 1.19 & 0.79 & Latvia & 31 & 51 & 41 & 1.46 & 1.26 & 0.87 \\
\hline Lithuania & 24 & - & 31 & - & 1.29 & - & Lithuania & 25 & - & 39 & - & 1.41 & - \\
\hline Estonia & 32 & 38 & 26 & 1.14 & 0.8 & 0.7 & Estonia & 31 & 41 & 24 & 1.2 & 0.76 & 0.64 \\
\hline Total & 23 & 27 & 23 & 1.29 & 0.97 & 0.75 & & 26 & 31 & 26 & 1.30 & 0.97 & 0.75 \\
\hline
\end{tabular}

${ }^{a}$ Prevalence rates were standardized using the 2013 European Standard population

${ }^{\mathrm{b}}$ The risk ratios are derived after fitting logistic regressions using the post-estimation command adjrr in STATA. The models are stratified by country and include age and survey as covariates. The ARRs are derived from the survey coefficients. All models include robust standard errors. Prevalences with $95 \%$ CIs are included in Table A2 in ESM. Significant values in bold $(p<0.05)$

inequalities (Table 4). Comparing the ARRs between the models with and without adjustment for this survey characteristic shows no reduction for EU-SILC and ESS and a small reduction for EHIS (ARR: 158 vs. 1.61) for men. For women, adjusting for survey characteristics shows small reduction for EHIS (ARR 1.51 vs. 1.57) and ESS (ARR 1.52 vs. AR 1.55), but a small increase for EU-SILC (1.77 vs. 1.73$)$.

\section{Rank comparison}

Table 5 shows that the ranks of both prevalence and inequalities given by the surveys do not agree, with correlations close to 0 in most cases. For the prevalence, only the rank comparison between EHIS and ESS for men is close to being statistically significant (Tau $=0.36$ and $p$ value $=0.07$ ). For the compassion of educational 


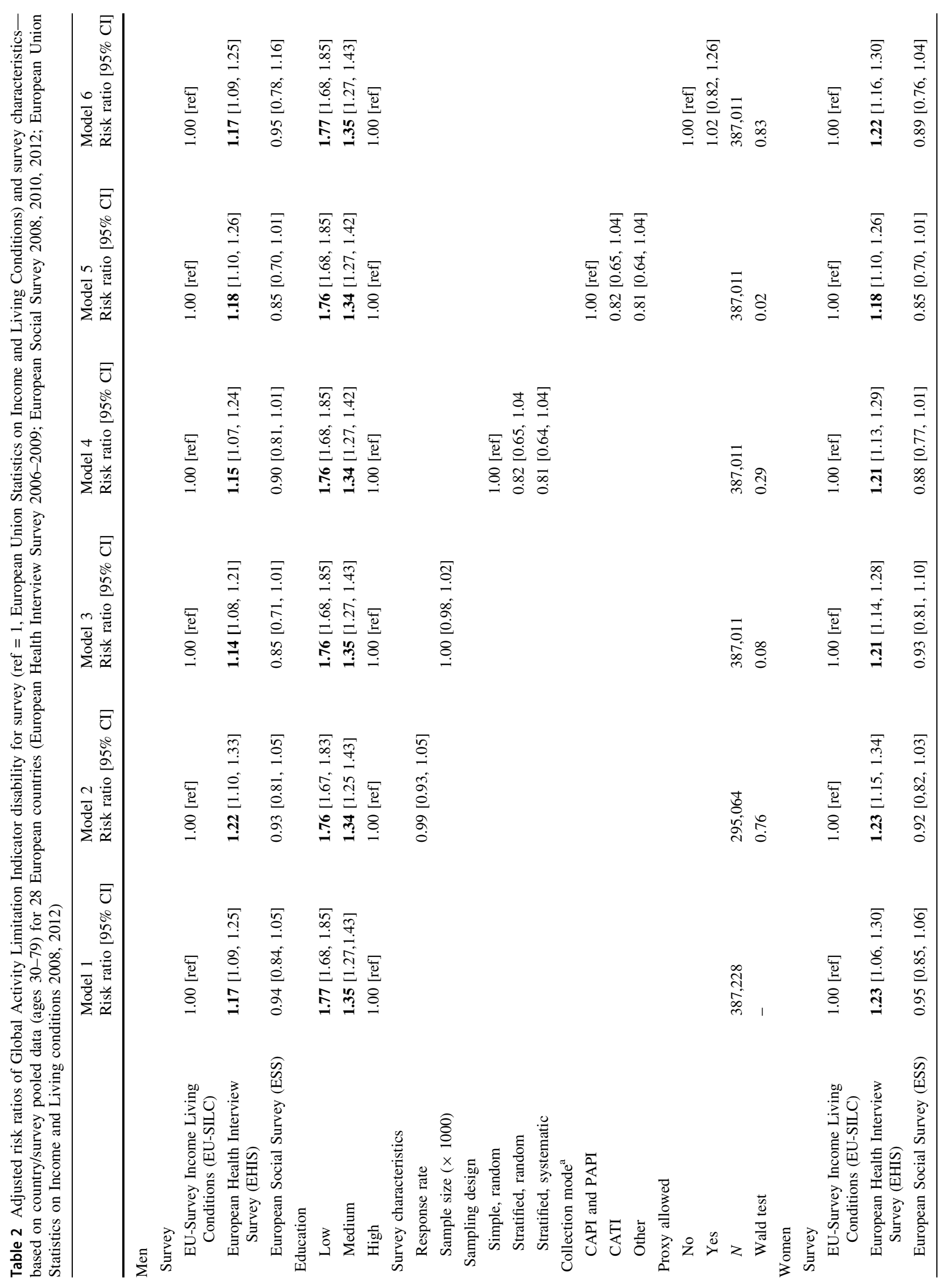




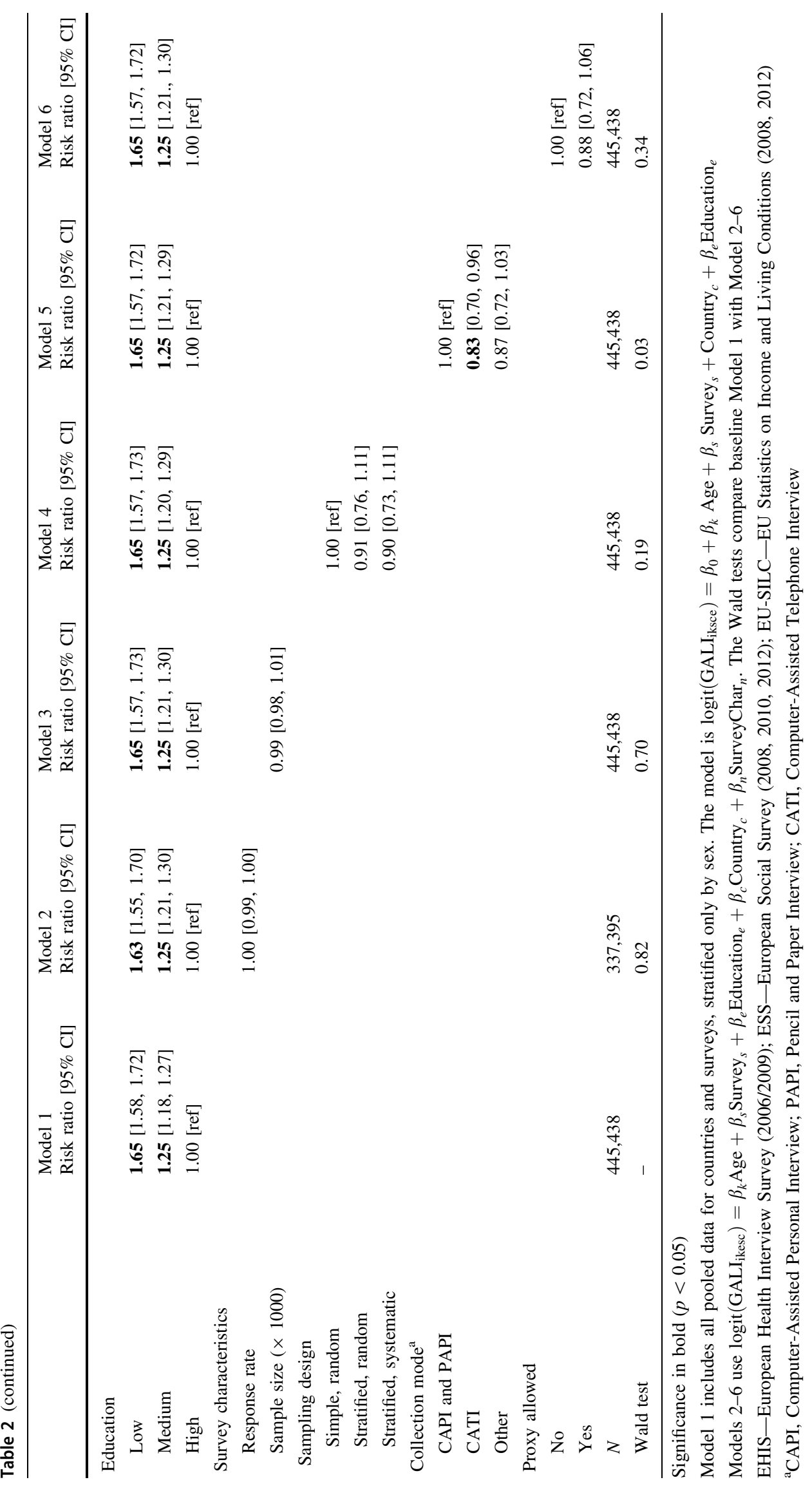


Table 3 Prevalence analysis stratified by education

\begin{tabular}{|c|c|c|c|c|c|c|}
\hline \multirow{2}{*}{$\begin{array}{l}\text { Survey } \\
\text { Men }\end{array}$} & \multicolumn{2}{|c|}{$\begin{array}{l}\text { Model A } \\
\text { Low educated }\end{array}$} & \multicolumn{2}{|c|}{$\begin{array}{l}\text { Model B } \\
\text { Medium educated }\end{array}$} & \multicolumn{2}{|c|}{$\begin{array}{l}\text { Model C } \\
\text { High educated }\end{array}$} \\
\hline & & & & & & \\
\hline $\begin{array}{l}\text { EU-Survey Income Living Conditions } \\
\text { (EU-SILC) }\end{array}$ & 1.00 & Ref & 1.00 & Ref & 1.00 & Ref \\
\hline $\begin{array}{l}\text { European Health Interview Survey } \\
\text { (EHIS) }\end{array}$ & 1.07 & {$[1.01,1.13]$} & 1.22 & {$[1.13,1.32]$} & 1.31 & {$[1.19,1.42]$} \\
\hline European Social Survey (ESS) & 0.88 & {$[0.81,0.97]$} & 0.97 & {$[0.83,1.11]$} & 1.07 & {$[0.95,1.22]$} \\
\hline$n$ & \multicolumn{2}{|c|}{119,290} & \multicolumn{2}{|c|}{180,158} & \multicolumn{2}{|c|}{87,563} \\
\hline \multicolumn{7}{|l|}{ Women } \\
\hline $\begin{array}{l}\text { EU-Survey Income Living Conditions } \\
\text { (EU-SILC) }\end{array}$ & 1.00 & Ref & 1.00 & Ref & 1.00 & Ref \\
\hline $\begin{array}{l}\text { European Health Interview Survey } \\
\text { (EHIS) }\end{array}$ & 1.15 & {$[1.10,1.21]$} & 1.35 & {$[1.16,1.56]$} & 1.36 & {$[1.19,1.54]$} \\
\hline European Social Survey (ESS) & 0.91 & {$[0.83,0.99]$} & 0.97 & {$[0.84,1.12]$} & 1.06 & {$[0.81,1.26]$} \\
\hline$n$ & \multicolumn{2}{|c|}{156,327} & \multicolumn{2}{|c|}{190,606} & \multicolumn{2}{|c|}{98,505} \\
\hline
\end{tabular}

Adjusted risk ratio of disability prevalence (between surveys) for the pooled dataset, stratified by education for men and women (ages 30-79) for 28 European countries (European Health Interview Survey 2006-2009; European Social Survey 2008, 2010, 2012; European Union Statistics on Income and Living conditions 2008, 2012)

Significance at the $5 \%$ level in bold

Models are stratified by sex and education

The models presented correspond to logit(Global Activity Limitation Indicator - GALI $)=\beta_{k}$ Age $_{k}+\beta_{s}$ Survey $_{s}+\beta_{c}$ Country $_{c}$

EHIS-European Health Interview Survey (2006/2009); ESS—European Social Survey (2008, 2010, 2012); EU-SILC-EU Statistics on Income and Living Conditions (2008, 2012) for 28 European countries (Finland, Sweden, Norway, Denmark, the UK, Ireland, the Netherlands, Belgium, Germany, Austria, Switzerland, France, Spain, Portugal, Italy, Greece, Cyprus, Slovenia, Croatia Czech Republic, Slovakia, Hungary, Poland, Bulgaria, Romania, Latvia, Lithuania, Estonia)

inequalities, the exception is the rank comparison between ESS and EHIS which is statistically significantly correlated at the $5 \%$ level, though with relatively low Kendall's tau of 0.40 .

\section{Discussion}

\section{Summary of findings}

EHIS estimates around $17 \%$ (men) and $23 \%$ (women) higher average prevalence of GALI disability than EUSILC; $24 \%$ (men) and 29\% (women) than ESS, whereas prevalence is not statistically significantly different between EU-SILC and ESS. The analyses stratified by education show that ESS estimates lower prevalence relative to EU-SILC only for the low educated; and that EHIS estimates higher prevalence across all educational groups, but more marked for the high educated than for the low educated. There is no agreement between surveys in ranking of countries by average prevalence.

On average, EU-SILC estimates the highest educational inequalities in GALI disability $(\mathrm{ARR}=1.93$ for men; $\mathrm{ARR}=1.73$ for women $)$, followed by EHIS $(\mathrm{ARR}=1.61$ for men; $\mathrm{ARR}=1.57$ for women $)$ and $\mathrm{ESS}(\mathrm{ARR}=1.57$
Fig. 1 Relative educational inequalities (low vs. high educated aged 30-79) in disability prevalence in 28 European countries by gender and survey (European Health Interview Survey 2006-2009; European Social Survey 2008, 2010, 2012; European Union Statistics on Income and Living conditions 2008, 2012)

for men; $A R R=1.55$ for women). Educational inequalities are statistically significantly different between surveys for several countries.

There is no agreement between surveys in ranking of countries by educational inequalities in GALI prevalence, with the exception of a small positive correlation between EHIS and ESS for men (Kendall's Tau = 0.40).

We observe a statistically significant association of GALI disability with collection mode of the survey, with remote interviewer (CATI) associated with lower GALI prevalence relative to present interviewer (PAPI and CAPI). However, the inclusion of survey characteristics does not account for the observed differences between surveys in prevalence or inequalities.

\section{Strengths and weaknesses}

This is the first systematic analysis of the agreement of 3 European surveys in their estimates of GALI prevalence 
Males

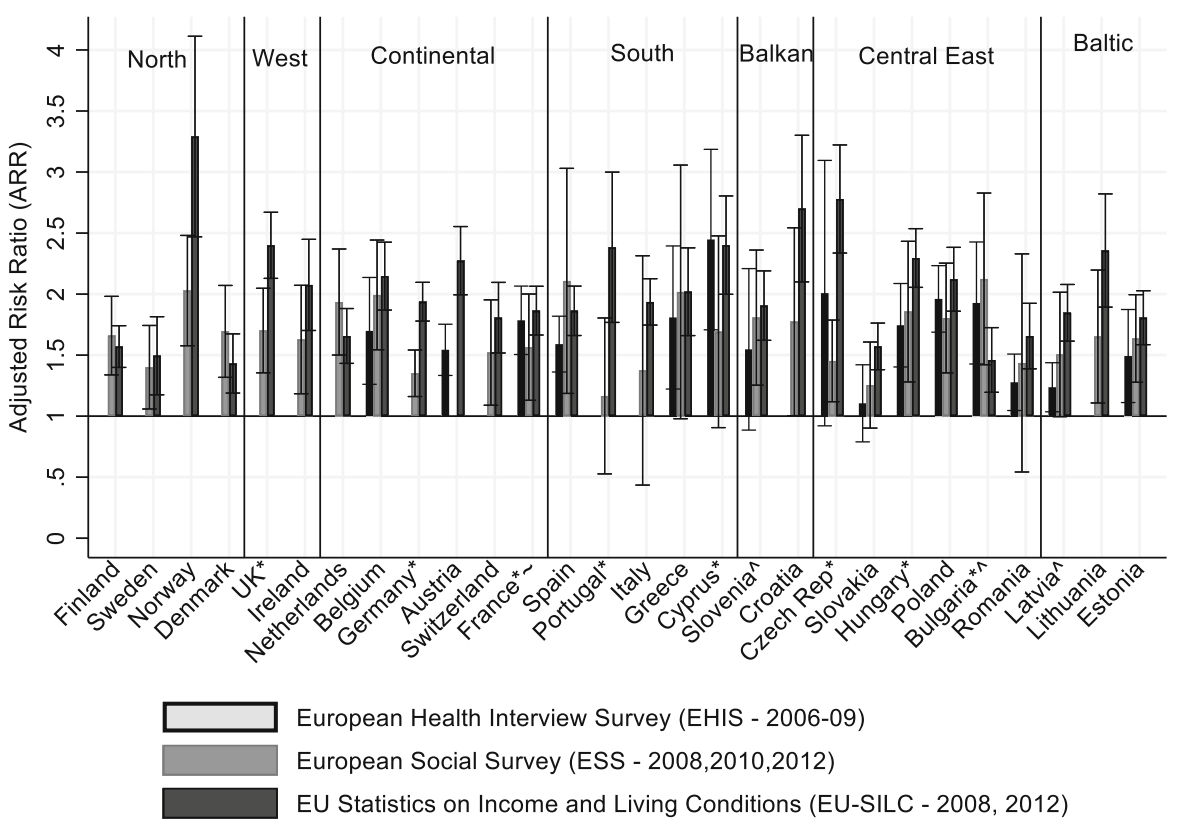

Likelihood Ratio Test (LR) significance at $5 \%$ level for pairs of surveys:

*EU-SILC vs ESS ^EU-SILC vs EHIS EHIS vs ESS

\section{Females}

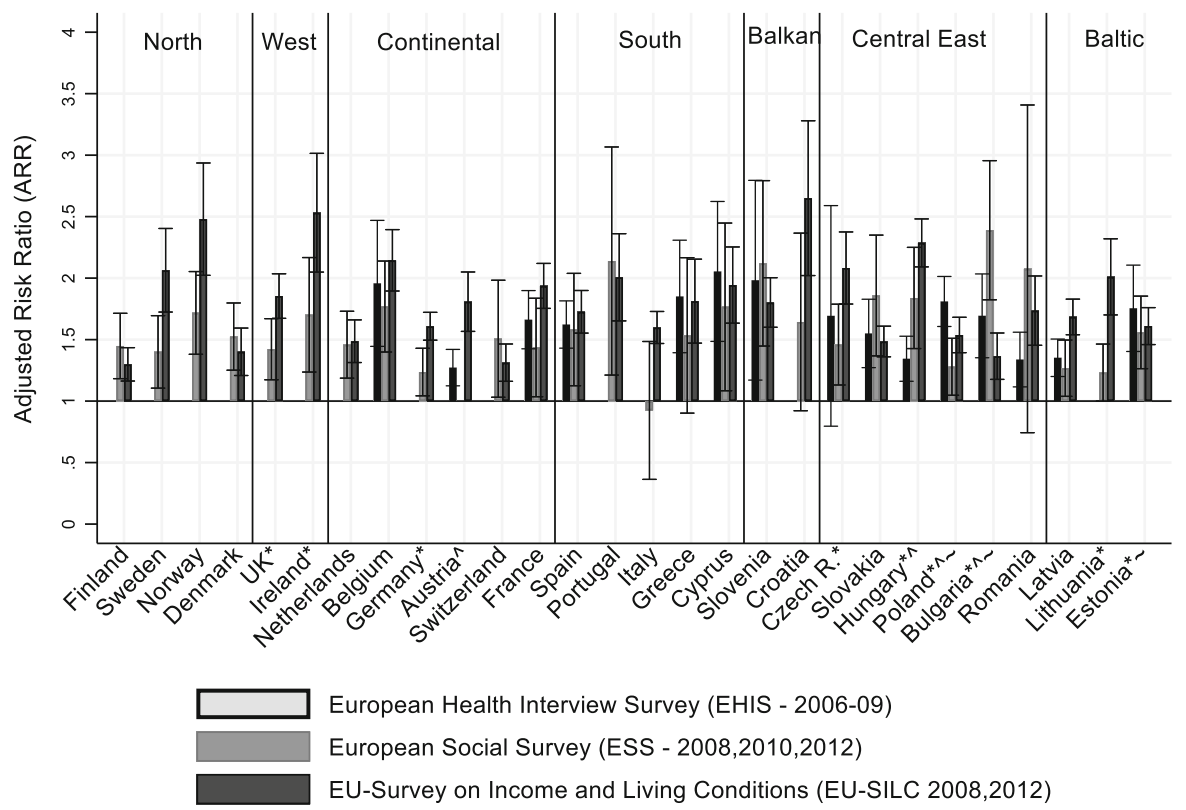

The educational ARRs for each country and survey are obtained using: logit(GALI -

Global Activity Limitation Indicator $\left.{ }_{i k e}\right)=\beta_{k}$ Age $_{k}+\beta_{e}$ Education $_{e}$ in models stratified by sex, country and survey. Figures were produced using STATA version 14

The LR tests comparing pairs of survey are stratified by sex and country and use the model logit $\left(G A L I_{i k e s}\right)=\beta_{k} A g e+$ $\beta_{e}$ Education $_{e}+\beta_{s}$ Survey $_{s}+\beta_{\text {se }}$ Survey $_{s} *$ Education $_{e}$. The baseline model is logit $\left(\right.$ GALI $\left._{i k e s}\right)=\beta_{k}$ Age + $\beta_{e}$ Education $_{e}+\beta_{s}$ Survey $_{s}$ 


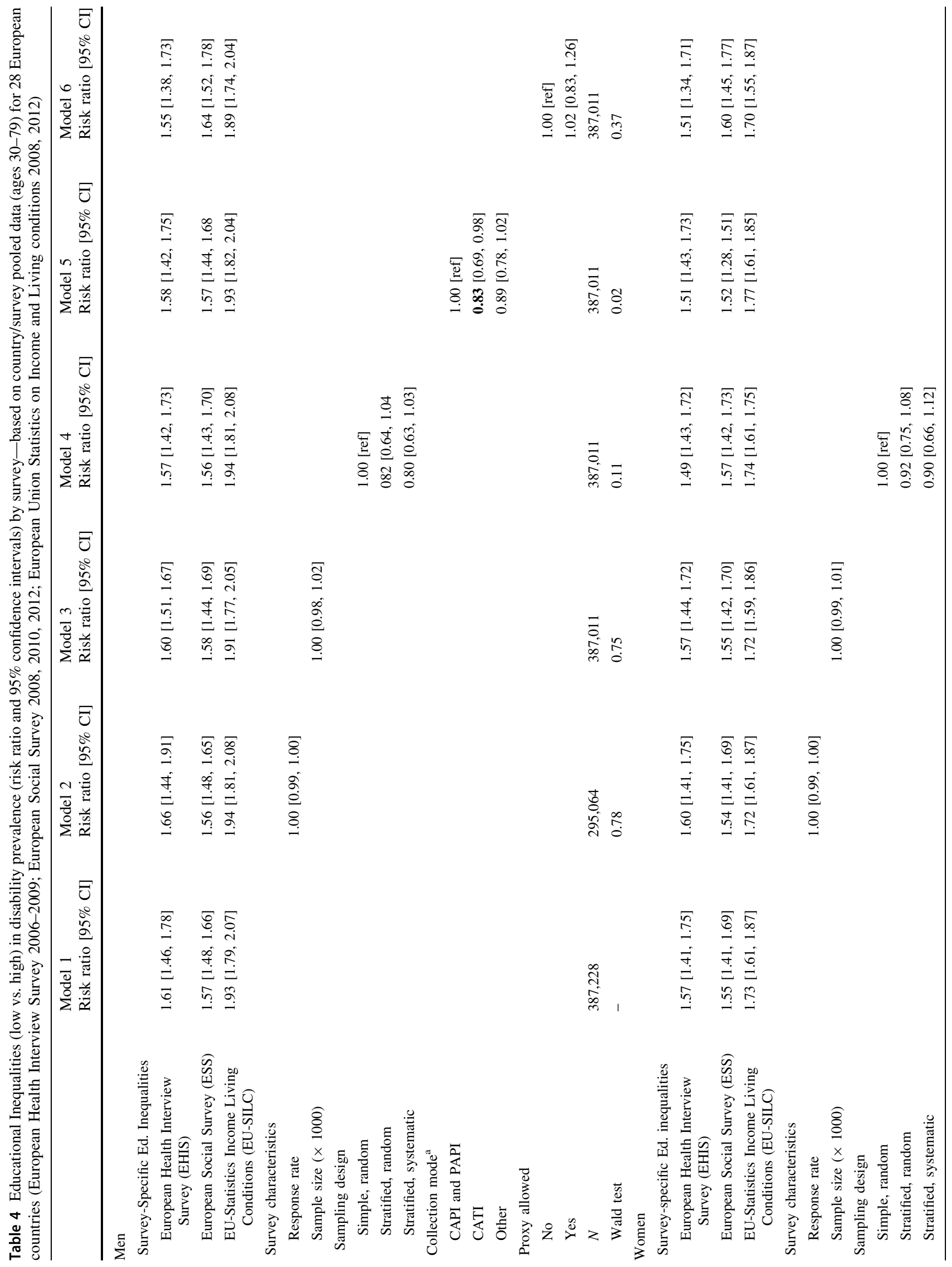




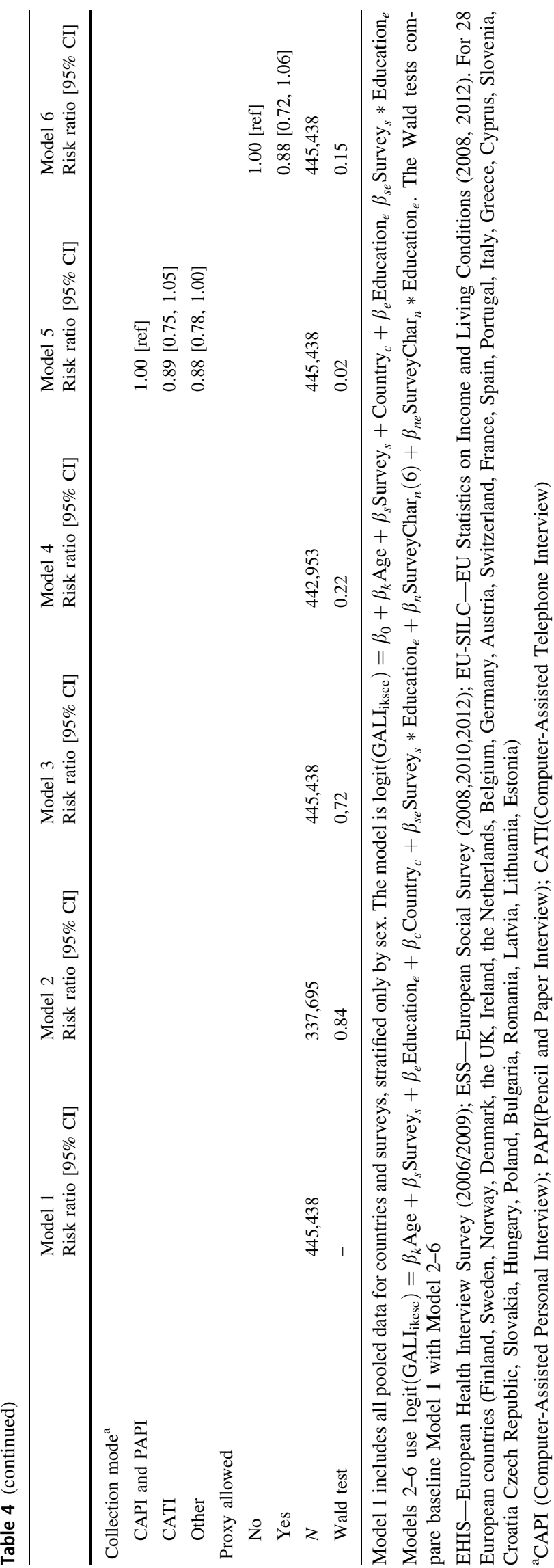

and educational inequalities. Unlike previous studies, we used micro-level data to explore variations both in relative (ARRs) and absolute (ARDs) terms. This is desirable considering that odds ratios (ORs) tend to be artificially high in the case of non-rare conditions (Tajeu et al. 2012) and that risk ratios are preferred over ORs as measures in epidemiologic studies. Additionally, we have used a structured framework to compare country-specific and average differences in GALI prevalence and inequalities as well as their association with survey characteristics, and have explicitly compared country rankings for these outcomes.

Limitations of the study include our inability to study the effect of differences in phrasing of the GALI question. We could not include GALI question differences in the pooled analyses with all surveys because there was no variation in GALI phrasing within EHIS (uses GALI standard phrasing throughout) and ESS (omits time reference throughout). We examined whether GALI phrasing significantly explained variation in GALI disability within EU-SILC, but we were unable to detect a statistically significant association (Online Resource 6). Omission of dimensions of the GALI question (being limited, in activities people usually do, because of health problems, for at least the past 6 months), as well as changes in wording and separation of the dimensions into several questions, has been shown to have an important effect on how individuals respond to self-reported questions (Cambois et al. 2016a; EHLEIS 2011; McClendon and O'Brien 1988).

\section{Interpretation of findings and comparison with previous studies}

There are important differences in the prevalence and the educational inequalities of GALI disability between the surveys included in the analysis. These differences have not been explained by the survey characteristics included in our models. There are other factors that are hard to capture that could explain the observed differences in prevalence and inequalities of GALI disability. For instance, the nature of the surveys is different from one another. ESS has extensive information on beliefs, attitudes and behaviors of Europeans, while EHIS is rich in health-related questions and EU-SILC focuses more on socioeconomic and income variables. This means that the context of the survey where the GALI question is being asked varies across surveys, with respondents being primed with other types of questions that could alter their response to the GALI question. The context in which the survey takes place, the wording and format of the question and even adjacent questions have been shown to matter in the responses individuals provide to self-reports (Schwarz 1999). 
Table 5 Kendal's Tau Correlations and associated $p$ value comparing country rank agreement (risk ratio) between surveys (European Health Interview Survey 2006-2009; European Social Survey 2008, 2010, 2012; European Union Statistics on Income and Living

\begin{tabular}{|c|c|c|c|c|c|c|c|}
\hline \multicolumn{4}{|c|}{ Prevalence (Kendall's tau ${ }^{\mathrm{b}}$ and $p$ value) } & \multicolumn{4}{|c|}{ Educational inequalities (Kendall's Tau ${ }^{\mathrm{b}}$ and $p$ value) } \\
\hline Pair of Surveys & Kendall's Tau ( -1 to 1$)$ & $p$ value & $n^{\mathrm{a}}$ & Pair of surveys & Kendall's Tau ( -1 to 1$)$ & $p$ value & $n^{\mathrm{a}}$ \\
\hline Men & & & & Men & & & \\
\hline EU-SILC versus ESS & 0.13 & 0.31 & 27 & EU-SILC versus ESS & -0.06 & 0.67 & 27 \\
\hline EU-SILC versus EHIS & -0.16 & 0.42 & 15 & EU-SILC versus EHIS & 0.12 & 0.55 & 15 \\
\hline EHIS versus ESS & 0.36 & 0.07 & 14 & EHIS versus ESS & 0.40 & 0.04 & 14 \\
\hline Women & & & & Women & & & \\
\hline EU-SILC versus ESS & -0.04 & 0.77 & 27 & EU-SILC versus ESS & -0.03 & 0.86 & 27 \\
\hline EU-SILC versus EHIS & 0.03 & 0.92 & 15 & EU-SILC versus EHIS & 0.25 & 0.19 & 15 \\
\hline EHIS versus ESS & -0.01 & 1.00 & 14 & EHIS versus ESS & 0.18 & 0.38 & 14 \\
\hline
\end{tabular}

Significance in bold $(p<0.05)$

EHIS-European Health Interview Survey (2006/2009); ESS—European Social Survey (2008, 2010, 2012); EU-SILC-EU Statistics on Income and Living Conditions $(2008,2012)$ for 28 European countries (Finland, Sweden, Norway, Denmark, the UK, Ireland, the Netherlands, Belgium, Germany, Austria, Switzerland, France, Spain, Portugal, Italy, Greece, Cyprus, Slovenia, Croatia Czech Republic, Slovakia, Hungary, Poland, Bulgaria, Romania, Latvia, Lithuania, Estonia)

${ }^{a}$ Countries without a pair are excluded from the rank comparison

${ }^{\mathrm{b}} \mathrm{A}$ value of -1 indicates complete reversal between the two ranks being compared, 0 that the ranks are independent of each other, and 1 that they completely agree

Although survey characteristics did not significantly explain the reported differences, we found a significant association between prevalence of GALI disability and mode of data collection. The results indicate that surveys conducted by a remote interviewer (CATI) are associated with lower prevalence when compared to present interviewers (PAPI, CAPI). Prior research has shown that collection mode has an impact on data quality (Bowling 2005), as well as on response rate: Response rates are higher in face-to-face interviews (Demarest et al. 2013), and lower in telephone interviews (Sykes and Collins 1988).

Our results are consistent with previous studies that used SRH. Croezen et al. find that prevalence of SRH is significantly different between the three surveys they compare and find associations with several survey characteristics (response rate, sample size, collection mode). Toch-Marquardt (2017) finds something similar for prevalence of SRH and for occupational inequalities, and finds no consistency in regional patterns. The choice of survey has a major impact on the conclusions we draw both about prevalence and health inequalities. This is the case when looking at both educational and occupational inequalities in health. Furthermore, our analyses of the ranking of countries by survey also indicate that the conclusions we draw of best and worst performers are also affected by the choice of survey. This has important implications for the monitoring of health and cross-national comparisons. conditions 2008, 2012) for prevalence and educational inequalities-based on country/survey pooled data (ages 30-79) for 28 European countries 
all three surveys estimate a higher prevalence for Latvia and Slovenia, and a lower prevalence for Cyprus. For educational inequalities, both ESS and EU-SILC estimate high risk ratios for Norway for men and Portugal and Slovenia for women.

Although we were unable to detect statistically significant effects of sample size and response rate, it is objectively desirable that both are optimized given financial constraints. This increases the accuracy of population health measurements and minimizes the risk of bias. From this perspective, it is perhaps legitimate to put more confidence in larger sample surveys with higher response rates like EU-SILC or EHIS. ESS has smaller sample sizes which also complicates working at subpopulation levels (Robine et al. 2003), particularly when stratifying by country, gender and education. However, ESS has other advantages, like a higher degree of ex ante harmonization than EU-SILC, whereas EHIS is conducted infrequently.

It is still unclear whether population levels of disability can be reliably measured with self-reports. The lack of agreement in prevalence and inequalities in disability and self-reported health calls for caution when using these surveys for cross-country comparisons.

\section{Conclusions and recommendations}

We find that both prevalence and educational inequalities of GALI disability are significantly affected by the choice of survey. We arrive to different interpretations of the health status of a country, its relative position to other countries and the size of educational inequalities depending on what survey is used for the measurement. This has important implications for population health monitoring, as well as developing valid comparisons across countries.

Our findings add to existing literature that investigated the comparability of SRH and has determined that this selfreported measure also varies significantly across other widely used European surveys. Further study is necessary to elucidate the causes of these discrepancies, and further harmonization of wording of the GALI question is necessary. Meanwhile, one should be very cautious in using these surveys for cross-country comparisons of (inequalities in) GALI disability.

Acknowledgements This study was conducted as part of the LIFEPATH project, which has been financially supported by the European Commission (Horizon 2020 Grant No. 633666). The funders had no role in study design, data collection and analysis, decision to publish, or preparation of the manuscript. The following data from the European Social Survey were used: ESS Round 4: European Social Survey Round 4 Data (2008). Data file edition 4.4. ESS Round 5: European Social Survey Round 5 Data (2010). Data file edition 3.3. ESS Round 6: European Social Survey Round 6 Data (2012). Data file edition 2.3. NSD-Norwegian Centre for Research Data, Norway_-Data Archive and distributor of ESS data for ESS ERIC. This study is based on data from Eurostat, European Union Statistics on Income and Living Conditions survey, reference years 2008 and 2012 and the European Health Interview Survey (EHIS) reference year 2006/2009. The responsibility for all conclusions drawn from the data lies entirely with the authors.

\section{Compliance with ethical standards}

Conflict of interest The authors declare that they have no conflict of interest.

Open Access This article is distributed under the terms of the Creative Commons Attribution 4.0 International License (http://creative commons.org/licenses/by/4.0/), which permits unrestricted use, distribution, and reproduction in any medium, provided you give appropriate credit to the original author(s) and the source, provide a link to the Creative Commons license, and indicate if changes were made.

\section{References}

Berger N, Van Oyen H, Cambois E, Fouweather T, Jagger C, Nusselder W, Robine J-M (2015) Assessing the validity of the Global Activity Limitation Indicator in fourteen European countries. BMC Med Res Methodol 15:1

Bowling A (2005) Mode of questionnaire administration can have serious effects on data quality. J Public Health 27:281-291

Brønnum-Hansen $\mathrm{H}$ et al (2015) Educational inequalities in health expectancy during the financial crisis in Denmark. Int J Public Health 60(8):927-935

Cambois E, Grobon S, Van Oyen H, Robine J-M (2016a) Impact of question wording on the measurement of activity limitation: evidence from a randomized test in France. J Aging Health 28:1315-1338

Cambois E, Solé-Auró A, Robine J-M (2016b) Economic hardship and educational differentials in disability in 26 European countries. J Aging Health 28:1214-1238

Croezen S, Burdorf A, van Lenthe FJ (2016) Self-perceived health in older Europeans: Does the choice of survey matter? Eur J Public Health 26:686-692

Croux C, Dehon C (2010) Influence functions of the Spearman and Kendall correlation measures. Stat Methods Appl 19:497-515

Demarest S, Van der Heyden J, Charafeddine R, Drieskens S, Gisle L, Tafforeau J (2013) Methodological basics and evolution of the Belgian health interview survey 1997-2008. Arch Public Health 71:24. https://doi.org/10.1186/0778-7367-71-24

EHLEIS (2011) Assesment of the GALI Question used in SILC since 2008. EHLEIS Technical Report

ESS (2016) ESS methodological overview. http://www.europeanso cialsurvey.org/methodology. Accessed 9 July 2016

Eurostat (2016) EU statistics on income and living conditions (EUSILC) methodology. http://ec.europa.eu/eurostat/statisticsexplained/index.php/EU_statistics_on_income_and_living_con ditions_(EU-SILC)_methodology. Accessed 9 July 2016

Hyder AA, Puvanachandra P, Morrow RH (2012) Measuring the health of populations: explaining composite indicators. J Public Health Res 1:222

Jürges H (2007) True health vs. response styles: exploring crosscountry differences in self-reported health. Health Econ $16: 163-178$

Kulik MC et al (2014) Does the pattern of educational inequalities in smoking in Western Europe depend on the choice of survey? Int J Public Health 59(4):587-597 
McClendon MJ, O'Brien DJ (1988) Question-order effects on the determinants of subjective well-being. Public Opin Q 52:351-364

Norton EC, Miller MM, Kleinman LC (2013) Computing adjusted risk ratios and risk differences in Stata. Stata J 13:492-509

Robine J-M, Jagger C, Mathers CD, Crimmins EM, Suzman RM (2003) Determining health expectancies. Wiley, Hoboken

Schwarz N (1999) Self-reports: how the questions shape the answers. Am Psychol 54:93

Sykes W, Collins M (1988) Effects of mode of interview: experiments in the UK. In: Groves RM, Biemer PP, Lyberg LE, Massey JT, Nicholls WL, Waksberg J (eds) Telephone survey methodology. Wiley, New York, pp 301-320

Tajeu GS, Sen B, Allison DB, Menachemi N (2012) Misuse of odds ratios in obesity literature: an empirical analysis of published studies. Obesity 20:1726-1731
Toch-Marquardt M (2017) Does the pattern of occupational class inequalities in self-reported health depend on the choice of survey? A comparative analysis of four surveys and 35 European countries. Eur J Public Health 27:34-39

Van Oyen H, Bogaert P, Yokota RTC et al. (2018) Measuring disability: a systematic review of the validity and reliability of the Global Activity Limitations Indicator (GALI). Arch Public Health 76(1):25

Publisher's Note Springer Nature remains neutral with regard to jurisdictional claims in published maps and institutional affiliations. 